\title{
Pharmacological Properties of Protocatechuic Acid and Its Potential Roles as Complementary Medicine
}

\author{
Yoswaris Semaming, ${ }^{1,2}$ Patchareewan Pannengpetch, ${ }^{3}$ \\ Siriporn C. Chattipakorn, ${ }^{2,4,5}$ and Nipon Chattipakorn ${ }^{2,5,6}$ \\ ${ }^{1}$ Veterinary Technology Program, Faculty of Technology, Udon Thani Rajabhat University, Udon Thani 41000, Thailand \\ ${ }^{2}$ Cardiac Electrophysiology Research and Training Center, Faculty of Medicine, Chiang Mai University, Chiang Mai 50200, Thailand \\ ${ }^{3}$ Department of Pharmacology, Faculty of Medicine, Khon Kaen University, Khon Kaen 40002, Thailand \\ ${ }^{4}$ Department of Oral Biology and Diagnostic Science, Faculty of Dentistry, Chiang Mai University, Chiang Mai 50200, Thailand \\ ${ }^{5}$ Center of Excellence in Cardiac Electrophysiology Research, Chiang Mai University, Chiang Mai 50200, Thailand \\ ${ }^{6}$ Cardiac Electrophysiology Unit, Department of Physiology, Faculty of Medicine, Chiang Mai University, Chiang Mai 50200, Thailand
}

Correspondence should be addressed to Nipon Chattipakorn; nchattip@gmail.com

Received 25 November 2014; Accepted 19 January 2015

Academic Editor: Sonia Piacente

Copyright (C) 2015 Yoswaris Semaming et al. This is an open access article distributed under the Creative Commons Attribution License, which permits unrestricted use, distribution, and reproduction in any medium, provided the original work is properly cited.

\begin{abstract}
This paper reviews the reported pharmacological properties of protocatechuic acid (PCA, 3,4-dihydroxy benzoic acid), a type of phenolic acid found in many food plants such as olives and white grapes. PCA is a major metabolite of anthocyanin. The pharmacological actions of PCA have been shown to include strong in vitro and in vivo antioxidant activity. In in vivo experiments using rats and mice, PCA has been shown to exert anti-inflammatory as well as antihyperglycemic and antiapoptotic activities. Furthermore, PCA has been shown to inhibit chemical carcinogenesis and exert proapoptotic and antiproliferative effects in different cancerous tissues. Moreover, in vitro studies have shown PCA to have antimicrobial activities and also to exert synergistic interaction with some antibiotics against resistant pathogens. This review aims to comprehensively summarize the pharmacological properties of PCA reported to date with an emphasis on its biological properties and mechanisms of action which could be therapeutically useful in a clinical setting.
\end{abstract}

\section{Introduction}

Protocatechuic acid (PCA, 3,4-dihydroxybenzoic acid) is a phenolic compound found in many food plants such as Olea europaea (olives), Hibiscus sabdariffa (roselle), Eucommia ulmoides (du-zhong), Citrus microcarpa Bunge (calamondin), and Vitis vinifera (white wine grapes) [1-3]. PCA content varies considerably depending on the type of food.

Recently, several investigations have shown that PCA is a major metabolite of complex polyphenols, especially anthocyanins $[4,5]$. Anthocyanins have been shown to affect a variety of physiological activities which are of great benefit to health, including a reduced risk of cardiovascular diseases. This particular beneficial effect is partly due to the antiinflammatory properties [6-8], antioxidant and free radical scavenging activities [9-12], peroxidation inhibition [13], and estrogenic/antiestrogenic activity [14] of PCA. PCA is of particular nutritional interest since it is a main anthocyanin metabolite that can reach tissues in amounts which can exert biological effects on health [15]. In vivo studies demonstrated that male balb/cA mice which were fed a standard diet supplemented with PCA for 12 weeks showed increased PCA levels in plasma and tissues such as brain, heart, liver, and kidney [16]. Moreover, PCA itself has been shown to possess antioxidant properties as well as having other potential health benefits such as anti-inflammatory effects.

The aim of this review is to comprehensively summarize the pharmacological properties of PCA reported to date including antioxidant, anti-inflammatory, antihyperglycemia, antiapoptosis/proapoptosis, and antimicrobial activities, with an emphasis on the biological properties and mechanisms of action which could be potentially useful in a clinical setting. 
TABLE 1: Summary of in vitro studies of antioxidant activities of PCA.

\begin{tabular}{|c|c|c|c|c|c|}
\hline Model & Method & $\begin{array}{c}\text { PCA } \\
\text { concentration }\end{array}$ & Major finding & Interpretation & Reference \\
\hline $\begin{array}{l}\text { Biochemical } \\
\text { assay }\end{array}$ & $\begin{array}{l}\text { (i) TBAR assay } \\
\text { (ii) } \mathrm{H}_{2} \mathrm{O}_{2} \text { assay } \\
\text { (iii) } \mathrm{DPPH}^{\cdot} \text { assay }\end{array}$ & $\begin{array}{c}0.05 \text { and } \\
0.10 \mathrm{mg} / \mathrm{mL}\end{array}$ & $\begin{array}{l}\text { (i) PCA increased \% inhibition of } \\
\text { lipid peroxidation } \\
\text { (ii) PCA increased \% scavenging of } \\
\mathrm{H}_{2} \mathrm{O}_{2} \\
\text { (iii) PCA increased \% scavenging of } \\
\text { DPPH }\end{array}$ & $\begin{array}{l}\text { PCA exerted antioxidant } \\
\text { activity }\end{array}$ & {$[22]$} \\
\hline $\begin{array}{l}\text { J774 A.1 } \\
\text { macrophages }\end{array}$ & $\begin{array}{l}\text { J774 A.1 } \\
\text { macrophages }\end{array}$ & $\begin{array}{c}3 \text { and } \\
25 \mathrm{~mol} / \mathrm{L}\end{array}$ & $\begin{array}{l}\text { (i) PCA decreased oxidation of LDL } \\
\text { (ii) PCA inhibited } \mathrm{O}_{2} \text { and } \mathrm{H}_{2} \mathrm{O}_{2} \\
\text { production } \\
\text { (iii) PCA increased GSH content } \\
\text { (iv) PCA restored GR and GPx } \\
\text { activities } \\
\text { (v) PCA restored the } \gamma \text {-GCS mRNA, } \\
\text { GR, and GPx expression }\end{array}$ & $\begin{array}{l}\text { PCA had an antioxidant } \\
\text { activity via activation of } \\
\text { mRNA transcription of } \\
\text { GSH-related enzymes }\end{array}$ & [23] \\
\hline $\begin{array}{l}\text { J774 A.1 } \\
\text { macrophages }\end{array}$ & $\begin{array}{l}\text { Direct PCA } \\
\text { application to } \\
\text { cells }\end{array}$ & $25 \mu \mathrm{M}$ & $\begin{array}{l}\text { (i) PCA increased GSH, GPx, and } \\
\text { GR expression } \\
\text { (ii) PCA increased Nrf } 2 \text { expression } \\
\text { and activation } \\
\text { (iii) PCA increased JNK mRNA } \\
\text { level }\end{array}$ & $\begin{array}{l}\text { PCA increased } \\
\text { macrophage endogenous } \\
\text { antioxidants via } \\
\text { JNK-mediated Nrf2 } \\
\text { activation }\end{array}$ & [24] \\
\hline $\begin{array}{l}\text { Human } \\
\text { neuronal cell } \\
\text { line }\end{array}$ & $\begin{array}{l}\mathrm{H}_{2} \mathrm{O}_{2} \text {-induced } \\
\text { oxidative stress }\end{array}$ & $\begin{array}{c}25,50, \text { and } \\
100 \mu \mathrm{M}\end{array}$ & $\begin{array}{l}\text { (i) PCA inhibited ROS formation at } \\
\text { cytosolic level } \\
\text { (ii) PCA inhibited apoptotic events } \\
\text { (iii) PCA improved mitochondrial } \\
\text { function } \\
\text { (iv) PCA decreased DNA } \\
\text { fragmentation }\end{array}$ & $\begin{array}{l}\text { PCA reduced apoptosis } \\
\text { via ROS reduction, } \\
\text { improved mitochondrial } \\
\text { function, and inhibited } \\
\text { DNA fragmentation }\end{array}$ & {$[25]$} \\
\hline PC12 cells & $\begin{array}{l}\mathrm{H}_{2} \mathrm{O}_{2} \text {-induced } \\
\text { oxidative damage }\end{array}$ & $\begin{array}{l}50,100,150, \\
\text { and } 200 \mu \mathrm{M}\end{array}$ & $\begin{array}{l}\text { (i) PCA increased cell viability } \\
\text { (ii) PCA decreased \% LDH release }\end{array}$ & $\begin{array}{l}\text { PCA prevented } \\
\mathrm{H}_{2} \mathrm{O}_{2} \text {-induced cell death }\end{array}$ & [26] \\
\hline BNLCL2 cells & $\begin{array}{l}\mathrm{H}_{2} \mathrm{O}_{2} \text {-induced } \\
\text { oxidative damage }\end{array}$ & $\begin{array}{l}1,5,10,20, \\
\text { and } \\
100 \mu \mathrm{g} / \mathrm{mL}\end{array}$ & $\begin{array}{l}\text { (i) PCA affected DPPH scavenging } \\
\text { activity } \\
\text { (ii) PCA inhibited liposome } \\
\text { peroxidation } \\
\text { (iii) PCA reduced intracellular ROS } \\
\text { level }\end{array}$ & $\begin{array}{l}\text { PCA had a radical } \\
\text { scavenging activity and } \\
\text { antioxidant property }\end{array}$ & {$[27]$} \\
\hline
\end{tabular}

\section{Antioxidant Activity of PCA}

Oxidative stress plays a key role in the pathogenesis of degenerative diseases such as cardiovascular diseases, diabetes mellitus, neurodegenerative diseases, cancer, and aging [1721]. Mounting evidence from both in vitro and in vivo studies demonstrates that PCA exerts potent antioxidative effects. In in vitro studies, as summarized in Table 1, PCA was shown to have free radical scavenging and antioxidant activities by decreasing lipid peroxidation and increasing the scavenging of hydrogen peroxide $\left(\mathrm{H}_{2} \mathrm{O}_{2}\right)$ and diphenylpicrylhydrazyl (DPPH) [22]. In J77A.1 macrophage, PCA decreased oxidized low-density lipoprotein levels (LDL), inhibited superoxide $\left(\mathrm{O}_{2}{ }^{\circ}\right)$ and $\mathrm{H}_{2} \mathrm{O}_{2}$ production, and also restored glutathione (GSH) related enzymes via c-Jun N-terminal kinase (JNK) mediated nuclear factor (erythroid-derived 2) like 2 (Nrf2) activation $[23,24]$. PCA also reduced reactive oxygen species (ROS) induced apoptosis by improving mitochondrial function, inhibiting DNA fragmentation in $\mathrm{H}_{2} \mathrm{O}_{2}$-induced oxidative stress in human neuronal cells [25], preventing lactate dehydrogenase ( $\mathrm{LDH}$ ) release in $\mathrm{H}_{2} \mathrm{O}_{2}$-induced oxidative stress in PC12 cells [26], and inhibiting intracellular ROS level in BNLCL2 cells [27].

Consistent with in vitro reports, in vivo studies (as summarized in Table 2) also demonstrated that PCA treatment decreased oxidative stress by promoting endogenous antioxidant enzymes in aging rats and also reduced $\mathrm{H}_{2} \mathrm{O}_{2}$-induced oxidative damage in aging mice, thus indicating that PCA could prevent oxidative damage in aging animals $[26,28]$. PCA also decreased advance glycation end products (AGEs) and ROS production in D-galactose-induced ROS and AGEs formation in mice [29]. In streptozotocin (STZ) induced diabetic rats, PCA was also found to decrease ROS formation in liver, heart, kidney, and brain by restoring endogenous antioxidant enzyme activities [3, 30]. All of these findings indicated that the PCA possess potential antioxidant activity, suggesting that it could be used as a complementary medication to prevent oxidative damage in various degenerative diseases. 
TABLE 2: Summary of in vivo studies of antioxidant activities of PCA.

\begin{tabular}{|c|c|c|c|c|c|}
\hline Model & Method & $\begin{array}{l}\text { PCA dose/ } \\
\text { route/ } \\
\text { duration }\end{array}$ & Major finding & Interpretation & Reference \\
\hline $\begin{array}{l}\text { Sprague- } \\
\text { Dawley } \\
\text { rat }\end{array}$ & $\begin{array}{l}\text { STZ-induced T1DM } \\
(50 \mathrm{mg} / \mathrm{kg}, \mathrm{ip})\end{array}$ & $\begin{array}{c}50,100 \mathrm{mg} / \mathrm{kg} \\
\text { po }\end{array}$ & $\begin{array}{l}\text { (i) PCA decreased plasma MDA } \\
\text { (ii) PCA decreased cardiac MDA } \\
\text { (iii) PCA decreased mitochondrial ROS } \\
\text { production }\end{array}$ & $\begin{array}{l}\text { PCA deceased oxidative } \\
\text { stress in T1DM rats }\end{array}$ & {$[30]$} \\
\hline $\begin{array}{l}\text { Sprague- } \\
\text { Dawley } \\
\text { rat }\end{array}$ & $\begin{array}{l}\mathrm{H}_{2} \mathrm{O}_{2} \text {-induced } \\
\text { oxidative damage in } \\
\text { young and age rats }\end{array}$ & $\begin{array}{l}5 \mathrm{mg} / \mathrm{kg} / \text { day } \\
\text { for } 7 \text { days (ip) }\end{array}$ & $\begin{array}{l}\text { (i) PCA improved scores during the passive } \\
\text { avoidance testing } \\
\text { (ii) PCA decreased MDA in brain of aged rat } \\
\text { (iii) PCA increased GSH-PX activity }\end{array}$ & $\begin{array}{l}\text { PCA promoted } \\
\text { endogenous antioxidant } \\
\text { enzymatic activities and } \\
\text { inhibited ROS } \\
\text { generation }\end{array}$ & {$[26]$} \\
\hline Mice & $\begin{array}{l}\text { D-galactose-induced } \\
\text { ROS and AGEs }\end{array}$ & $\begin{array}{l}0.5 \%, 1 \% \text {, or } \\
2 \% \text { in diet for } 8 \\
\text { weeks }\end{array}$ & $\begin{array}{l}\text { (i) PCA decreased ROS and protein carbonyl } \\
\text { content } \\
\text { (ii) PCA retained GSH content } \\
\text { (iii) PCA decreased CML, pentosidine, sorbitol, } \\
\text { fructose, and methylglycoxal level in brain }\end{array}$ & $\begin{array}{l}\text { PCA had antiglycative } \\
\text { and antioxidant activity } \\
\text { by retaining GSH }\end{array}$ & [29] \\
\hline Mice & Young and aged & $\begin{array}{l}5 \text { and } 10 \mathrm{mg} / \mathrm{kg} \\
\text { (ip) for } 7 \text { days }\end{array}$ & $\begin{array}{l}\text { In aged rats } \\
\text { (i) PCA elevated splenic weight } \\
\text { (ii) PCA increased the activities of GSH-PX } \\
\text { (iii) PCA increased catalase (CAT) activity } \\
\text { (iv) PCA decreased malondialdehyde } \\
\text { (MDA) level }\end{array}$ & $\begin{array}{l}\text { PCA was a potential } \\
\text { antiageing agent by } \\
\text { promoting endogenous } \\
\text { antioxidant enzymatic } \\
\text { activities }\end{array}$ & [28] \\
\hline Mice & $\begin{array}{l}\text { STZ-induced DM } \\
(50 \mathrm{mg} / \mathrm{kg} / \mathrm{iv})\end{array}$ & $\begin{array}{l}1 \%, 2 \% \text {, and } \\
4 \% \text { in diet for } 8 \\
\text { weeks }\end{array}$ & $\begin{array}{l}\text { (i) PCA at all concentrations decreased cardiac } \\
\text { and renal MDA level } \\
\text { (ii) PCA at } 2 \% \text { and } 4 \% \text { increased cardiac and } \\
\text { renal GSH level } \\
\text { (iii) PCA at } 2 \% \text { and } 4 \% \text { decreased cardiac and } \\
\text { renal GSSG formation } \\
\text { (iv) PCA at } 2 \% \text { and } 4 \% \text { increased GPX and } \\
\text { catalase activity in cardiac and renal tissues }\end{array}$ & $\begin{array}{l}\text { PCA had an } \\
\text { antioxidative effect } \\
\text { through the restoration } \\
\text { of endogenous } \\
\text { antioxidants }\end{array}$ & [3] \\
\hline
\end{tabular}

\section{Anti-Inflammatory Activity of PCA}

The inflammatory process is regulated by coordinated activation of both pro- and anti-inflammatory mediators in tissue cells (such as fibroblasts, endothelial cells, tissue macrophages, and mast cells) and also by the recruitment of leucocytes [31, 32]. Prolonged activation of proinflammatory mediators causes tissue injury and organ dysfunction. As a consequence, chronic inflammation plays a critical role in the pathophysiology of major chronic diseases including obesity, cardiovascular disease, diabetes mellitus, Alzheimer's disease, and many types of cancer $[33,34]$. The mediators, including nitric oxide (NO), lipid mediators, cytokines/chemokines, adhesion molecules, and matrix metalloproteinases (MMPs), are involved in the initiation, maintenance, and resolution of the inflammatory process $[35,36]$.

A summary of in vitro studies regarding the effects of PCA on the inflammatory process is shown in Table 3. PCA was shown to suppress tumor necrosis factor alpha (TNF- $\alpha$ ), interleukin- (IL-) $1 \beta$, inducible nitric oxide synthase (iNOS), and cyclooxygenase 2 (COX-2) expression via the regulation of the nuclear factor kappa-light-chain-enhancer of activated $B$ cells (NF-kB) and mitogen-activated protein kinase (MAPK) activation in lipopolysaccharide- (LPS-) induced RAW 264.7 cell damage [37]. Moreover, PCA also suppressed vascular cell adhesion protein 1 (VCAM-1) and intercellular adhesion molecule 1 (ICAM-1) mRNA expression in
TNF- $\alpha$-induced cellular damage [38] and inhibited monocyte infiltration [39].

Consistent with in vitro reports, animal studies (Table 4) demonstrated that PCA strongly inhibited inflammation by inhibiting carrageenan-induced inflammation in mice by decreasing TNF- $\alpha$, IL- $1 \beta$, and prostaglandin E2 (PGE 2 ) levels, suppressed iNOS and COX-2 expression in apolipoprotein E (ApoE) deficient mice [37], prevented LPS-induced sepsis in mice via decreased NO levels and suppressed IL10 [40], reduced VCAM-1 and ICAM-1 [38], and inhibited monocyte/macrophage infiltration in mice [39]. Moreover, PCA also prevented coagulation and inflammation in STZinduced diabetic rats by inhibiting the plasma levels of the plasminogen activator inhibitor 1 (PAI-1), antithrombin III (AT-III), protein C, C-reactive protein (CRP), and von Willebrand factor (vWF) and reduced IL-6, TNF- $\alpha$, and monocyte chemoattractant protein-1 (MCP-1) levels in the heart and kidneys [3]. These findings suggest that the antiinflammatory effects of PCA might be beneficial in various chronic degenerative diseases in which the inflammatory process plays an important part in the pathogenesis.

\section{Antihyperglycemic Activity of PCA}

Maintenance of glucose homeostasis by strict hormonal control is of the utmost importance to human physiology 
TABLE 3: Summary of in vitro studies of anti-inflammatory activities of PCA.

\begin{tabular}{|c|c|c|c|c|c|}
\hline Model & Method & $\begin{array}{c}\text { PCA } \\
\text { concentration }\end{array}$ & Major finding & Interpretation & Reference \\
\hline $\begin{array}{l}\text { RAW } \\
264.7 \text { cells }\end{array}$ & $\begin{array}{l}\text { Lipopolysaccharide- } \\
\text { (LPS-) induced } \\
\text { cellular damage }\end{array}$ & $\begin{array}{l}1,2,5 \text {, and } \\
25 \mu \mathrm{M}\end{array}$ & $\begin{array}{l}\text { (i) PCA decreased TNF- } \alpha \text { and IL-1 } \beta \\
\text { (ii) PCA decreased NO and PGE } 2 \\
\text { (iii) PCA inhibited iNOS and COX-2 } \\
\text { expression } \\
\text { (iv) PCA inhibited IkB- } \alpha \text { degradation } \\
\text { (v) PCA inhibited NF-kB } \\
\text { phosphorylation } \\
\text { (vi) PCA inhibited p38, ERK, and JNK }\end{array}$ & $\begin{array}{l}\text { PCA had } \\
\text { anti-inflammatory } \\
\text { effects by regulating } \\
\text { NF-kB and MAPK } \\
\text { activation }\end{array}$ & [37] \\
\hline $\begin{array}{l}\text { Mouse } \\
\text { aortic } \\
\text { endothe- } \\
\text { lial cell } \\
\text { (MAEC) }\end{array}$ & $\begin{array}{l}\text { TNF- } \alpha \text {-induced } \\
\text { cellular damage }\end{array}$ & $\begin{array}{l}0.05,0.5,5.0 \\
10,20, \text { and } \\
40 \mu \mathrm{mol} / \mathrm{L}\end{array}$ & $\begin{array}{l}\text { (i) PCA inhibited adhesion of HL- } 60 \text { cells } \\
\text { to MAECs } \\
\text { (ii) PCA suppressed VCAM-1 and } \\
\text { ICAM-1 mRNA expression } \\
\text { (iii) PCA reduced NF-kB activation }\end{array}$ & $\begin{array}{l}\text { PCA had an } \\
\text { anti-inflammatory effect } \\
\text { by inhibiting monocyte } \\
\text { adhesion molecules }\end{array}$ & [38] \\
\hline $\begin{array}{l}\text { Cell } \\
\text { culture }\end{array}$ & $\begin{array}{l}\text { Isolated peripheral } \\
\text { blood monocytes } \\
\text { (PBMs) from } \\
\text { ApoE-deficient mice }\end{array}$ & $\begin{array}{c}0.125,0.25 \text {, and } \\
0.5 \mu \mathrm{mol} / \mathrm{L}\end{array}$ & $\begin{array}{l}\text { (i) PCA decreased CCR2 protein and } \\
\text { mRNA expression } \\
\text { (ii) PCA inhibited mouse PBMs } \\
\text { migration }\end{array}$ & $\begin{array}{l}\text { PCA exerted } \\
\text { antiatherogenic } \\
\text { properties by inhibiting } \\
\text { monocyte infiltration }\end{array}$ & [39] \\
\hline
\end{tabular}

TABLE 4: Summary of in vivo studies of anti-inflammatory activities of PCA.

\begin{tabular}{|c|c|c|c|c|c|}
\hline Model & Method & $\begin{array}{l}\text { PCA dose/ } \\
\text { route/ } \\
\text { duration }\end{array}$ & Major finding & Interpretation & Reference \\
\hline Mice & $\begin{array}{l}\text { Carrageenan- } \\
\text { induced } \\
\text { inflammation in } \\
\text { BALB/c mice }\end{array}$ & $\begin{array}{l}5 \text { and } \\
25 \mathrm{mg} / \mathrm{kg} \\
\text { po }(24 \mathrm{~h})\end{array}$ & $\begin{array}{l}\text { (i) PCA reduced exudate } \\
\text { (ii) PCA decreased protein content } \\
\text { (iii) PCA reduced leukocyte number } \\
\text { (iv) PCA inhibited TNF- } \alpha \text {, IL-1 } \beta \text {, and } \text { PGE }_{2} \\
\text { level } \\
\text { (v) PCA inhibited COX-2 and NF-kB } \\
\text { expression }\end{array}$ & $\begin{array}{l}\text { PCA exerted } \\
\text { anti-inflammatory } \\
\text { effects by inhibiting } \\
\text { NF-kB activation. }\end{array}$ & [37] \\
\hline Mice & $\begin{array}{l}\text { ApoE-deficient } \\
\text { mice }\end{array}$ & $\begin{array}{l}0.033 \% \\
(w / w) \text { of } \\
\text { diet for } 20 \\
\text { weeks }\end{array}$ & $\begin{array}{l}\text { (i) PCA reduced sinus plague area } \\
\text { (ii) PCA decreased cholesterol accumulation } \\
\text { in aortas } \\
\text { (iii) PCA reduced VCAM-1 and ICAM-1 } \\
\text { expression in aortas } \\
\text { (iv) PCA reduced NF-kB binding activity } \\
\text { (v) PCA reduced plasma-soluble VCAM-1 } \\
\text { and ICAM-1 levels }\end{array}$ & $\begin{array}{l}\text { PCA exerted } \\
\text { antiatherosclerosis } \\
\text { effects by inhibiting } \\
\text { adhesion molecules and } \\
\text { reducing NF-kB } \\
\text { activation }\end{array}$ & [38] \\
\hline Mice & $\begin{array}{l}\text { Thioglycollate- } \\
\text { induced peritonitis } \\
\text { in ApoE-deficient } \\
\text { mice }\end{array}$ & $\begin{array}{l}25 \mathrm{mg} / \mathrm{kg} \\
\text { (po) for } 11 \\
\text { days }\end{array}$ & $\begin{array}{l}\text { (i) PCA decreased CCR } 2 \text { protein and mRNA } \\
\text { expression in PBMs of ApoE-deficient mice } \\
\text { (ii) PCA reduced macrophage infiltration } \\
\text { into the abdominal cavity }\end{array}$ & $\begin{array}{l}\text { PCA exerted } \\
\text { antiatherogenic } \\
\text { properties by inhibiting } \\
\text { monocyte/macrophage } \\
\text { infiltration }\end{array}$ & [39] \\
\hline Mice & $\begin{array}{l}\text { LPS-induced sepsis } \\
(20 \mathrm{mg} / \mathrm{kg}, \mathrm{ip})\end{array}$ & $\begin{array}{l}50 \mathrm{mg} / \mathrm{kg} \\
\text { (ip) single } \\
\text { dose }\end{array}$ & $\begin{array}{l}\text { (i) PCA reduced lethality } \\
\text { (ii) PCA suppressed TNF- } \alpha \text { and IL-10 } \\
\text { (iii) PCA decreased plasma ALT levels } \\
\text { (iv) PCA decreased plasma nitrite/nitrate } \\
\text { levels } \\
\text { (v) PCA decreased hepatic MDA levels }\end{array}$ & $\begin{array}{l}\text { PCA exerted sepsis } \\
\text { prevention properties by } \\
\text { inhibiting inflammatory } \\
\text { cytokines and } \\
\text { antioxidant activity }\end{array}$ & {$[40]$} \\
\hline Mice & $\begin{array}{l}\text { STZ-induced DM } \\
(50 \mathrm{mg} / \mathrm{kg} / \mathrm{iv})\end{array}$ & $\begin{array}{l}1 \%, 2 \% \text {, and } \\
4 \% \text { in diet } \\
\text { for } 8 \text { weeks }\end{array}$ & $\begin{array}{l}\text { (i) PCA lowered plasma PAI-1 levels } \\
\text { (ii) PCA increased plasma AP-III levels } \\
\text { (iii) PCA increased plasma protein C levels } \\
\text { (iv) PCA lowered plasma CRP levels } \\
\text { (v) PCA decreased plasma von Willebrand } \\
\text { factor } \\
\text { (vi) PCA reduced IL-6, TNF- } \alpha \text {, and MCP-1 } \\
\text { levels in heart and kidney }\end{array}$ & $\begin{array}{l}\text { PCA exerted } \\
\text { anticoagulatory and } \\
\text { anti-inflammatory } \\
\text { effects by lowering } \\
\text { inflammatory cytokines }\end{array}$ & {$[3]$} \\
\hline
\end{tabular}


TABLE 5: Summary of in vitro study of antihyperglycemic activities of PCA.

\begin{tabular}{lllll}
\hline Model & Model/method & PCA concentration & Major finding & Interpretation \\
\hline & & (i) PCA increased glucose uptake & \\
$\begin{array}{l}\text { Human omental } \\
\text { adipocytes and }\end{array}$ & oxLDL-induced & (ii) PCA increased GLUT4 & PCA exerted an \\
$\begin{array}{l}\text { murine adipocyte } \\
\text { 3T3-L1 cells }\end{array}$ & insulin resistance & translocation & insulin-like activity in \\
& & (iii) PCA increased PPAR $\gamma$ & adipocytes by increasing \\
& & activity & [45] \\
& & (iv) PCA increased adiponectin & \\
\hline
\end{tabular}

TABLE 6: Summary of in vivo studies of antihyperglycemic activities of PCA.

\begin{tabular}{|c|c|c|c|c|c|}
\hline Model & Model/method & $\begin{array}{l}\text { PCA dose/ } \\
\text { route/ } \\
\text { duration }\end{array}$ & Major finding & Interpretation & Reference \\
\hline $\begin{array}{l}\text { Sprague- } \\
\text { Dawley } \\
\text { rat }\end{array}$ & $\begin{array}{l}\text { STZ-induced } \\
\text { T1DM } \\
(50 \mathrm{mg} / \mathrm{kg}, \mathrm{ip})\end{array}$ & $\begin{array}{l}50, \\
100 \mathrm{mg} / \mathrm{kg} \\
(\mathrm{po})\end{array}$ & $\begin{array}{l}\text { (i) PCA decreased FBG } \\
\text { (ii) PCA decreased } \mathrm{HbA}_{1 \mathrm{c}}\end{array}$ & $\begin{array}{l}\text { PCA exerted } \\
\text { hypoglycemic effects } \\
\text { in T1DM }\end{array}$ & {$[30]$} \\
\hline Mice & $\begin{array}{l}\text { STZ-induced } \\
\text { DM } \\
(50 \mathrm{mg} / \mathrm{kg}, \mathrm{iv})\end{array}$ & $\begin{array}{l}1 \%, 2 \% \text {, and } \\
4 \% \text { in diet } \\
\text { for } 8 \text { weeks }\end{array}$ & $\begin{array}{l}\text { (i) PCA lowered plasma glucose levels } \\
\text { (ii) PCA increased insulin levels } \\
\text { (iii) PCA decreased TG and TC content in } \\
\text { plasma, heart, and liver }\end{array}$ & $\begin{array}{l}\text { PCA attenuated } \\
\text { diabetic conditions by } \\
\text { lowering plasma } \\
\text { glucose, increasing } \\
\text { insulin, and lowering } \\
\text { triglyceride levels }\end{array}$ & {$[3]$} \\
\hline
\end{tabular}

\begin{tabular}{|c|c|c|c|c|}
\hline $\begin{array}{l}\text { Sprague- } \\
\text { Dawley } \\
\text { rat }\end{array}$ & $\begin{array}{l}\text { STZ-induced } \\
\text { DM } \\
(40 \mathrm{mg} / \mathrm{kg}, \mathrm{ip})\end{array}$ & $\begin{array}{c}50,100, \\
200 \mathrm{mg} / \\
\mathrm{kg} / \text { day (po) } \\
\text { for } 45 \text { days }\end{array}$ & $\begin{array}{l}\text { (i) PCA decreased plasma glucose levels } \\
\text { (ii) PCA decreased } \mathrm{HbA}_{1 \mathrm{l}} \text { levels } \\
\text { (iii) PCA increased plasma insulin levels } \\
\text { (iv) PCA increased hexokinase activity and } \\
\text { increased glycogen content in liver } \\
\text { (v) PCA decreased activity of glucose } \\
\text { 6-phosphatase and fructose 1,6-bisphosphatase in } \\
\text { liver } \\
\text { (vi) PCA reduced adipose tissue of DM pancreas } \\
\text { and normalized pancreatic islets }\end{array}$ & $\begin{array}{l}\text { PCA exerted } \\
\text { antihyperglycemic } \\
\text { effects by restoring } \\
\text { carbohydrate } \\
\text { metabolic enzyme } \\
\text { activity and } \\
\text { increasing plasma } \\
\text { insulin levels }\end{array}$ \\
\hline
\end{tabular}

(i) Content of PCA increased in plasma, brain, heart, liver, and kidney

(ii) PCA decreased water intake and food intake

(iii) PCA increased body weight

(iv) PCA decreased urine volume

(v) PCA reduced plasma glucose levels

(vi) PCA increased plasma insulin levels

(vii) PCA decreased plasma BUN level

(viii) PCA increased creatinine clearance rate

(ix) PCA decreased $\mathrm{HbA}_{1 \mathrm{C}}$ level

(x) PCA decreased urine glycated albumin

STZ-induced $\quad 2 \%$ and $4 \% \quad$ (xi) PCA reduced renal production of CML,

Mice

DM

in diet for 12

(50 mg/kg, iv) weeks pentosidine, sorbitol, and fructose

(xii) PCA decreased brain content of CML, pentosidine, fructose, and sorbitol

(xiii) PCA decreased urinary albumin

(xiv) PCA reduced level of fibronectin, type-IV

collagen, and TGF- $\beta$ in renal tissue

(xv) PCA reduced renal activity and expression of

$\mathrm{AR}$ and $\mathrm{SDH}$

(xvi) PCA increased renal activity and expression of GLI

(xvii) PCA decreased renal activity and mRNA expression of PKC- $\alpha$ and PKC- $\beta$

(xviii) PCA decreased RAGE mRNA expression
PCA had an antihyperglycemic, antiglycative and renoprotective effects via increasing plasma insulin, reducing plasma glucose, reducing renal level of glycation end products, fibronectin,

TGF- $\beta$, and repressing renal activity and expression of $\mathrm{AR}$, SDH, GLI, PKC- $\alpha$, PPAR- $\gamma$, restoring PPAR- $\gamma$, and suppressing RAGE 
TABLE 7: Summary of in vitro studies of antiapoptotic activities of PCA in noncancer cells.

\begin{tabular}{|c|c|c|c|c|c|}
\hline Model & Model/method & $\begin{array}{c}\text { PCA } \\
\text { concentration }\end{array}$ & Major finding & Interpretation & Reference \\
\hline $\begin{array}{l}\text { HUVECs } \\
\text { and Jurkat } \\
\text { cells }\end{array}$ & $\begin{array}{l}\text { TNF- } \alpha- \\
\text { induced cell } \\
\text { death }\end{array}$ & $\begin{array}{c}50,100 \mu \mathrm{M} \\
\text { and } 1 \mathrm{nM}\end{array}$ & $\begin{array}{l}\text { (i) PCA inhibited TNF- } \alpha \text {-induced HUVECs and } \\
\text { Jurkat cells death } \\
\text { (ii) PCA increased NF-kB activation } \\
\text { (iii) PCA increased degradation of IkB }\end{array}$ & $\begin{array}{l}\text { PCA exerted } \\
\text { cell-protective } \\
\text { effects via } \\
\text { increased IkB } \\
\text { degradation and } \\
\text { subsequent NF-kB } \\
\text { activation }\end{array}$ & [49] \\
\hline PC12 cells & $\begin{array}{l}\mathrm{MPP}^{+} \text {-induced } \\
\text { mitochondrial } \\
\text { dysfunction } \\
\text { and apoptotic } \\
\text { cell death }\end{array}$ & $\begin{array}{l}0.3,0.6, \text { and } \\
1.2 \mathrm{mM}\end{array}$ & $\begin{array}{l}\text { (i) PCA reduced the number of cell death } \\
\text { (ii) PCA at } 0.6 \text { and } 1.2 \mathrm{mM} \text { decreased percentage } \\
\text { of depolarized cell, reduced ROS formation, and } \\
\text { increased GSH content } \\
\text { (iii) PCA at } 0.6 \text { and } 1.2 \mathrm{mM} \text { decreased caspase- } 3 \\
\text { activity and increased Bcl-2 protein }\end{array}$ & $\begin{array}{l}\text { PCA exerted } \\
\text { antiapoptotic } \\
\text { activities via } \\
\text { attenuated changes } \\
\text { of mitochondrial } \\
\text { membrane } \\
\text { permeability and } \\
\text { decreased oxidative } \\
\text { stress damage }\end{array}$ & {$[50]$} \\
\hline $\begin{array}{l}\text { Isolated } \\
\text { NSCs of } \\
\text { embryonic } \\
\text { rat }\end{array}$ & $\begin{array}{l}\text { Direct PCA } \\
\text { application to } \\
\text { cells }\end{array}$ & $\begin{array}{l}0.006,0.03 \\
0.06, \text { and } \\
0.12 \mathrm{mM}\end{array}$ & $\begin{array}{l}\text { (i) PCA at } 0.03,0.06 \text {, and } 0.12 \mathrm{mM} \text { increased } \\
\text { cellular viability } \\
\text { (ii) PCA reduced nuclear fragmentation } \\
\text { (iii) PCA reduced the levels of apoptosis } \\
\text { (iv) PCA decreased endogenous ROS level } \\
\text { (v) PCA decreased caspase- } 3 \text { activity }\end{array}$ & $\begin{array}{l}\text { PCA inhibited cell } \\
\text { apoptosis via } \\
\text { suppression of the } \\
\text { caspase cascade }\end{array}$ & [51] \\
\hline PC12 cells & $\begin{array}{l}\mathrm{H}_{2} \mathrm{O}_{2} \text {-induced } \\
\text { apoptosis }\end{array}$ & $\begin{array}{l}0.006,0.03 \\
0.06, \text { and } \\
0.12 \mathrm{mM}\end{array}$ & $\begin{array}{l}\text { (i) PCA (over } 0.3 \mathrm{mM} \text { ) increased cellular viability } \\
\text { (ii) PCA reduced LDH leakage } \\
\text { (iii) PCA reduced apoptotic sub-G1 population }\end{array}$ & $\begin{array}{l}\text { PCA promoted cell } \\
\text { viability and } \\
\text { inhibited apoptotic } \\
\text { cell death }\end{array}$ & {$[52]$} \\
\hline PC12 cells & $\begin{array}{l}\mathrm{MPP}^{+} \text {-induced } \\
\text { apoptotic cell } \\
\text { death }\end{array}$ & $\begin{array}{l}0.33,0.65 \text {, and } \\
1.30 \mathrm{mM}\end{array}$ & $\begin{array}{l}\text { (i) PCA reduced cell death in a dose-dependent } \\
\text { manner } \\
\text { (ii) PCA treatment exhibited normal cellular } \\
\text { morphology and normal mitochondria } \\
\text { (iii) PCA increased tyrosine hydroxylase } \\
\text { expression } \\
\text { (iv) PCA reduced oligomeric } \alpha \text {-synuclein } \\
\text { (v) PCA increased monomeric } \alpha \text {-synuclein }\end{array}$ & $\begin{array}{l}\text { PCA had } \\
\text { neuroprotective } \\
\text { effects via reducing } \\
\text { cell death and } \\
\text { inhibiting } \\
\text { oligomerization of } \\
\alpha \text {-synuclein }\end{array}$ & {$[53]$} \\
\hline $\begin{array}{l}\text { Rat } \\
\text { primary } \\
\text { hepatocytes }\end{array}$ & $\begin{array}{l}\text { t-BHP } \\
(1.5 \mathrm{mM}) \\
\text { induced } \\
\text { oxidative } \\
\text { damage }\end{array}$ & $\begin{array}{c}0.02,0.05, \text { and } \\
0.10 \mathrm{mg} / \mathrm{mL}\end{array}$ & $\begin{array}{l}\text { (i) PCA } 0.05 \text { and } 0.10 \mathrm{mg} / \mathrm{mL} \text { decreased } \mathrm{LDH} \text {, } \\
\text { ALT, and MDA } \\
\text { (ii) PCA prevented mitochondrial depolarization } \\
\text { (iii) PCA increased scavenging activity on DPPH }\end{array}$ & $\begin{array}{l}\text { PCA had a } \\
\text { cell-protective } \\
\text { effect via its } \\
\text { antioxidant and } \\
\text { scavenging activity }\end{array}$ & {$[54]$} \\
\hline
\end{tabular}

$[41,42]$. Failure of the control of glucose levels, with defects in both insulin action and insulin secretion, can result in a metabolic syndrome which is a multisymptom disorder of energy homeostasis [43]. It has been demonstrated that peroxisome proliferator-activated receptor gamma (PPAR $\gamma)$ is one of several targets of insulin activity, which regulates the expression and activity of key players in the maintenance of glucose transport machinery efficiency, such as glucose transporter (GLUT) 4 and adiponectin $[44,45]$. In in vitro studies, as summarized in Table 5, PCA has been shown to exert an insulin-like activity in oxidized LDL-induced insulin resistance in adipocytes via increased PPAR $\gamma$ activation [45]. Similarly, in vivo studies (Table 6) also demonstrated that PCA decreased blood glucose levels in STZ-induced diabetes via restored carbohydrate metabolic enzyme activity, increased plasma insulin level, and normalized the activity of pancreatic islets $[3,30,46]$. These findings suggest that PCA provides antihyperglycemic effects in addition to its reported antioxidant and anti-inflammatory effects.

\section{Antiapoptosis versus Proapoptotic Activity of PCA}

Polyphenols have been shown to improve cell survival and protect against cytotoxicity by inhibiting apoptosis [18]. However, they can also induce apoptosis and prevent tumor growth $[47,48]$. These opposite effects are mainly due to its effects on the controlling of the cell redox state. Evidence from in vitro studies (Table 7) revealed that PCA has cell-protective effects via increased $\mathrm{IkB}$ degradation and subsequent NF-kB activation in TNF- $\alpha$-induced cell death [49], attenuated changes of the mitochondrial membrane 
TABLE 8: Summary of in vitro studies of proapoptotic activity of PCA in cancer cells.

\begin{tabular}{|c|c|c|c|c|c|}
\hline Model & Model/method & $\begin{array}{l}\text { PCA } \\
\text { concentration }\end{array}$ & Major finding & Interpretation & Reference \\
\hline $\begin{array}{l}\text { HL-60 } \\
\text { leukemia } \\
\text { cells }\end{array}$ & $\begin{array}{l}\text { Direct PCA } \\
\text { application to } \\
\text { cells }\end{array}$ & $\begin{array}{l}0.2,0.5,1 \text {, and } \\
2 \mathrm{mM}\end{array}$ & $\begin{array}{l}\text { (i) PCA increased DNA fragmentation } \\
\text { (ii) PCA declined hyperphosphorylated } \\
\text { RB level } \\
\text { (iii) PCA reduced Bcl-2 protein } \\
\text { expression } \\
\text { (iv) PCA increased Bax protein } \\
\text { expression }\end{array}$ & $\begin{array}{l}\text { PCA had an } \\
\text { antiproliferative effect } \\
\text { via induced RB } \\
\text { phosphorylation and } \\
\text { degradation and Bcl-2 } \\
\text { protein suppression in } \\
\text { cancer cells }\end{array}$ & {$[55]$} \\
\hline $\begin{array}{l}\text { Human } \\
\text { gastric ade- } \\
\text { nocarcinoma } \\
\text { (AGS) cells }\end{array}$ & $\begin{array}{l}\text { Direct PCA } \\
\text { application to } \\
\text { cells }\end{array}$ & $\begin{array}{l}0.5,1.0,2.0 \\
4.0,6.0,8.0 \\
\text { and } 9.0 \mathrm{mM}\end{array}$ & $\begin{array}{l}\text { (i) PCA increased apoptotic bodies } \\
\text { formation } \\
\text { (ii) PCA increased p-JNK expression } \\
\text { (iii) PCA increased p-p53 expression } \\
\text { (iv) PCA increased phosphorylation of } \\
\text { ATF-2 at Thr }{ }^{69 / 71} \text { and c-Jun at Ser } \\
\text { (v) PCA increased Fas expression } \\
\text { (vi) PCA increased FasL expression } \\
\text { (vii) PCA decreased Bcl-2 expression } \\
\text { (viii) PCA increased Bax expression }\end{array}$ & $\begin{array}{l}\text { PCA induced } \\
\text { apoptosis via JNK/p38 } \\
\text { MAPK pathway, } \\
\text { activated Fas/FasL } \\
\text { pathway, increased } \\
\text { translocation of Bax, } \\
\text { and reduced Bcl-2 in } \\
\text { cancer cells }\end{array}$ & {$[56]$} \\
\hline $\begin{array}{l}\text { HepG2 hepa- } \\
\text { tocellular } \\
\text { carcinoma } \\
\text { cells }\end{array}$ & $\begin{array}{l}\text { Direct PCA } \\
\text { application to } \\
\text { cells }\end{array}$ & $\begin{array}{l}0,3,10,30, \\
100, \text { and } \\
300 \mu \mathrm{mol} / \mathrm{L}\end{array}$ & $\begin{array}{l}\text { (i) PCA decreased viability of HepG2 } \\
\text { hepatocellular carcinoma } \\
\text { (ii) PCA increased JNK and p53 } \\
\text { expression }\end{array}$ & $\begin{array}{l}\text { PCA induced cell } \\
\text { death via activating } \\
\text { JNK and p38 MAPK } \\
\text { pathways in cancer } \\
\text { cells }\end{array}$ & {$[57]$} \\
\hline $\begin{array}{l}\text { Human } \\
\text { breast, lung, } \\
\text { liver, cervix, } \\
\text { and prostate } \\
\text { cancer cells }\end{array}$ & $\begin{array}{l}\text { Direct PCA } \\
\text { application to } \\
\text { cells }\end{array}$ & $\begin{array}{l}1,2,4, \text { and } \\
8 \mu \mathrm{mol} / \mathrm{L}\end{array}$ & $\begin{array}{l}\text { (i) PCA decreased viability } \\
\text { (ii) PCA enhanced DNA fragmentation } \\
\text { (iii) PCA decreased MMP } \\
\text { (iv) PCA lowered } \mathrm{Na}^{+}-\mathrm{K}^{+} \text {-ATPase activity } \\
\text { (v) PCA increased caspase- } 3 \text { activity } \\
\text { (vi) PCA increased caspase- } 8 \text { activity } \\
\text { (vii) PCA decreased ICAM- } 1 \text { level } \\
\text { (viii) PCA at } 2,4 \text {, and } 8 \mu \mathrm{mol} / \mathrm{L} \text { decreased } \\
\text { VEGF level } \\
\text { (ix) PCA suppressed IL- } 6 \text { and IL- } 8 \text { levels }\end{array}$ & $\begin{array}{l}\text { PCA had anticancer } \\
\text { properties via } \\
\text { increased apoptosis or } \\
\text { suppressed invasion } \\
\text { and metastasis cancer } \\
\text { cells }\end{array}$ & {$[58]$} \\
\hline
\end{tabular}

permeability, decreased oxidative stress damage and increased Bcl-2 levels in 1-methyl-4-phenylpyridinium$\left(\mathrm{MPP}^{+}{ }_{-}\right)$induced apoptotic cell death [50], decreased caspase-3 activity in isolated neuronal stem cells (NSCs) [51], and reduced $\mathrm{LDH}$ leakage in $\mathrm{H}_{2} \mathrm{O}_{2}$-induced apoptosis [52]. In $\mathrm{MPP}^{+}$-induced cell death, PCA treatment resulted in a return to normal cellular morphology and normal mitochondria [53]. Moreover, PCA has been shown to have cellprotective effects via antioxidant and scavenging activities [54].

Unlike the cells described in Table 7, evidence from cancer cell studies (Table 8) demonstrated that PCA can induce apoptosis and prevent the growth of tumor cells via causing reduced $\mathrm{Bcl}-2$ protein, increased Bax protein expression in human leukemia (HL-60) cells [55], via activated JNK/p38 MAPK pathways and Fas/FasL pathways, increased translocation of Bax, and reduced Bcl-2 levels in human gastric adenocarcinoma cells [56] and via induced JNK and p38 MAPK pathways in HepG2 hepatocellular carcinoma cells [57]. Moreover, PCA also demonstrated anticancer properties by causing apoptosis or suppressing invasion and metastasis in human breast, lung, liver, cervix and prostate cancer cells [58]. Consistently, an in vivo study (Table 9) also demonstrated that PCA inhibited $N$-nitrosomethylbenzylamine (NMBA) induced esophageal tumorigenesis by its inhibitory effects on genes associated with inflammation in rats [59].

\section{Antimicrobial Activity of PCA}

In vitro studies (Table 10) demonstrated that PCA has an antimicrobial effect against gram positive and negative bacteria and fungi $[60,61]$. PCA also prevented contamination of meat by Campylobacter and aerobes, by decreasing lipid oxidation [62]. PCA exerted its antibacterial effects due to its ability to inhibit bacterial growth and increase the synergistic effects of antibiotics hence reducing the possibility of resistance to drugs [63]. These antimicrobial activities of PCA have been proposed as promising applications in both health protection and food preservation in order to avoid food-borne illnesses $[62,64]$. 
TABLE 9: Summary of in vivo studies of proapoptotic activity of PCA.

\begin{tabular}{llcll}
\hline Model & Method & $\begin{array}{c}\text { PCA dose/ } \\
\text { route/ } \\
\text { duration }\end{array}$ & Major finding & Interpretation \\
\hline Rat & PCA 0.05\% & $\begin{array}{l}\text { (i) PCA reduced area of hyperplasia } \\
\text { began at week 25 }\end{array}$ & $\begin{array}{l}\text { PCA prevented } \\
\text { esophageal } \\
\text { tumorigenesis, by } \\
\text { (ii) PCA reduced COX-2, iNOS, soluble }\end{array}$ & $\begin{array}{l}\text { inhibitory effects on } \\
\text { genes associated with } \\
\text { inflammation }\end{array}$ \\
\hline
\end{tabular}

TABLE 10: Summary of in vitro studies of antimicrobial activity of PCA.

\begin{tabular}{|c|c|c|c|c|c|}
\hline Model & Method & $\begin{array}{l}\text { PCA } \\
\text { concentration }\end{array}$ & Major finding & Interpretation & Reference \\
\hline $\begin{array}{l}\text { Campylobacter } \\
\operatorname{spp}\end{array}$ & $\begin{array}{l}\text { Antimicrobial } \\
\text { activity testing }\end{array}$ & $\begin{array}{l}\text { (i) } 10 \mathrm{mg} / \mathrm{mL} \\
\text { (ii) } 5, \\
10 \mathrm{mg} / 100 \mathrm{~g} \\
\text { beef }\end{array}$ & $\begin{array}{l}\text { (i) PCA inhibited growth and } \\
\text { susceptible and antibiotic-resistant } \\
\text { Campylobacter species } \\
\text { (ii) PCA inhibited growth of } \\
\text { aerobes in beef samples } \\
\text { (iii) PCA decreased lipid oxidation } \\
\text { levels in ground beef }\end{array}$ & $\begin{array}{l}\text { (i) PCA could preserve } \\
\text { foods to prevent } \\
\text { contamination by } \\
\text { Campylobacter and } \\
\text { aerobes, via decreased } \\
\text { lipid oxidation }\end{array}$ & {$[62]$} \\
\hline $\begin{array}{l}\text { Pseudomonas } \\
\text { aeruginosa }\end{array}$ & $\begin{array}{l}\text { Antimicrobial } \\
\text { susceptibility } \\
\text { testing }\end{array}$ & $2,000 \mu \mathrm{g} / \mathrm{mL}$ & $\begin{array}{l}\text { (i) PCA inhibited growth of } \\
\text { Pseudomonas aeruginosa } \\
\text { (ii) PCA plus sulfamethoxazole } \\
\text { increased synergistic mode of } \\
\text { inhibition of } P \text {. aeruginosa }\end{array}$ & $\begin{array}{l}\text { (i) PCA had an } \\
\text { antibacterial effect by } \\
\text { inhibiting bacterial } \\
\text { growth and increasing } \\
\text { the synergistic effects on } \\
\text { antibiotics to reduced } \\
\text { drug resistance }\end{array}$ & [63] \\
\hline $\begin{array}{l}\text { Bacteria and } \\
\text { fungi }\end{array}$ & $\begin{array}{l}\text { Antimicrobial } \\
\text { activity testing }\end{array}$ & $\begin{array}{l}1.22- \\
625 \mu \mathrm{g} / \mathrm{mL}\end{array}$ & $\begin{array}{l}\text { (i) PCA prevented } 80 \% \text { of the } \\
\text { growth of organisms }\end{array}$ & $\begin{array}{l}\text { (i) PCA had an } \\
\text { antimicrobial effect } \\
\text { against gram positive } \\
\text { and negative bacteria } \\
\text { and against fungi }\end{array}$ & {$[60]$} \\
\hline $\begin{array}{l}\text { Helicobacter } \\
\text { pylori }\end{array}$ & $\begin{array}{l}\text { Antimicrobial } \\
\text { susceptibility } \\
\text { testing }\end{array}$ & $8-64 \mathrm{mg} / \mathrm{L}$ & $\begin{array}{l}\text { (i) PCA inhibited growth of } H \text {. } \\
\text { pylori } \\
\text { (ii) PCA reduced drug-resistant } H \text {. } \\
\text { pylori } \\
\text { (iii) PCA at }(32-40 \mathrm{mg} / \mathrm{L}) \text { reduced } \\
\text { urease activity of } H \text {. pylori to } 40 \%\end{array}$ & $\begin{array}{l}\text { (i) PCA had growth } \\
\text { prevention effects on } H \text {. } \\
\text { pylori }\end{array}$ & {$[61]$} \\
\hline
\end{tabular}

\section{Conclusion}

Growing evidence suggests the significant biological potential of PCA through the modulation of cellular signals involved in the control of oxidative stress and inflammation. Moreover, its antiapoptotic effects in normal cells and proapoptotic effects in cancer cells suggest definite benefits as a potential chemotherapeutic agent. However, much evidence of such properties has been collected from cellular and animal studies, while clinical studies are still lacking. Future clinical studies are needed to warrant the clinical usefulness of the PCA.

\section{Conflict of Interests}

The authors declare that there is no conflict of interests regarding the publication of this paper.

\section{Acknowledgments}

This work was supported by the Thailand Research Fund RTA5580006 (NC) and BRG5780016 (SC), Chiang Mai University Center of Excellence Award (NC), Udon Thani Rajabhat University Fund (YS), and a NSTDA Research Chair Grant from the National Science and Technology Development Agency (NC).

\section{References}

[1] W.-L. Lin, Y.-J. Hsieh, F.-P. Chou, C.-J. Wang, M.-T. Cheng, and T.-H. Tseng, "Hibiscus protocatechuic acid inhibits lipopolysaccharide-induced rat hepatic damage," Archives of Toxicology, vol. 77, no. 1, pp. 42-47, 2003.

[2] L. A. Pacheco-Palencia, S. Mertens-Talcott, and S. T. Talcott, "Chemical composition, antioxidant properties, and thermal 
stability of a phytochemical enriched oil from Açai (Euterpe oleracea Mart.)," Journal of Agricultural and Food Chemistry, vol. 56, no. 12, pp. 4631-4636, 2008.

[3] P. Li, X. Q. Wang, H. Z. Wang, and Y. N. Wu, "High performance liquid chromatographic determination of phenolic acids in fruits and vegetables," Biomedical and Environmental Sciences, vol. 6, no. 4, pp. 389-398, 1993.

[4] P. Vitaglione, G. Donnarumma, A. Napolitano et al., "Protocatechuic acid is the major human metabolite of cyanidinglucosides," Journal of Nutrition, vol. 137, no. 9, pp. 2043-2048, 2007.

[5] R. C. Pimpao, T. Dew, M. E. Figueira et al., "Urinary metabolite profiling identifies novel colonic metabolites and conjugates of phenolics in healthy volunteers," Molecular Nutrition \& Food Research, vol. 58, no. 7, pp. 1414-1425, 2014.

[6] J. González-Gallego, M. V. García-Mediavilla, S. SánchezCampos, and M. J. Tuñó, "Fruit polyphenols, immunity and inflammation," British Journal of Nutrition, vol. 104, supplement 3, pp. S15-S27, 2010.

[7] R. Landberg, Q. Sun, E. B. Rimm et al., "Selected dietary flavonoids are associated with markers of inflammation and endothelial dysfunction in U.S. women," The Journal of Nutrition, vol. 141, no. 4, pp. 618-625, 2011.

[8] A. E. Rotelli, T. Guardia, A. O. Juárez, N. E. de la Rocha, and L. E. Pelzer, "Comparative study of flavonoids in experimental models of inflammation," Pharmacological Research, vol. 48, no. 6, pp. 601-606, 2003.

[9] M. Garcia-Alonso, A.-M. Minihane, G. Rimbach, J. C. RivasGonzalo, and S. de Pascual-Teresa, "Red wine anthocyanins are rapidly absorbed in humans and affect monocyte chemoattractant protein 1 levels and antioxidant capacity of plasma," The Journal of Nutritional Biochemistry, vol. 20, no. 7, pp. 521-529, 2009.

[10] H. Wang, M. G. Nair, G. M. Strasburg et al., "Antioxidant and antiinflammatory activities of anthocyanins and their aglycon, cyanidin, from tart cherries," Journal of Natural Products, vol. 62, no. 2, pp. 294-296, 1999.

[11] M. P. Kähkönen and M. Heinonen, "Antioxidant activity of anthocyanins and their aglycons," Journal of Agricultural and Food Chemistry, vol. 51, no. 3, pp. 628-633, 2003.

[12] H. Matsumoto, Y. Nakamura, M. Hirayama, Y. Yoshiki, and K. Okubo, "Antioxidant activity of black currant anthocyanin aglycons and their glycosides measured by chemiluminescence in a neutral $\mathrm{pH}$ region and in human plasma," Journal of Agricultural and Food Chemistry, vol. 50, no. 18, pp. 5034-5037, 2002.

[13] T. Tsuda, K. Shiga, K. Ohshima, S. Kawakishi, and T. Osawa, "Inhibition of lipid peroxidation and the active oxygen radical scavenging effect of anthocyanin pigments isolated from Phaseolus vulgaris L," Biochemical Pharmacology, vol. 52, no. 7, pp. 1033-1039, 1996.

[14] A. Cassidy, S. de Pascual Teresa, and G. Rimbach, "Molecular mechanisms by which dietary isoflavones potentially prevent atherosclerosis," Expert Reviews in Molecular Medicine, vol. 5, no. 24, pp. 1-15, 2003.

[15] C. D. Kay, P. A. Kroon, and A. Cassidy, "The bioactivity of dietary anthocyanins is likely to be mediated by their degradation products," Molecular Nutrition and Food Research, vol. 53, supplement 1, pp. S92-S101, 2009.

[16] C.-Y. Lin, S.-J. Tsai, C.-S. Huang, and M.-C. Yin, "Antiglycative effects of protocatechuic acid in the kidneys of diabetic mice,"
Journal of Agricultural and Food Chemistry, vol. 59, no. 9, pp. 5117-5124, 2011.

[17] M. B. Moura, L. S. dos Santos, and B. van Houten, "Mitochondrial dysfunction in neurodegenerative diseases and cancer," Environmental and Molecular Mutagenesis, vol. 51, no. 5, pp. 391-405, 2010.

[18] B. L. Queen and T. O. Tollefsbol, "Polyphenols and aging," Current Aging Science, vol. 3, no. 1, pp. 34-42, 2010.

[19] D. A. Patten, M. Germain, M. A. Kelly, and R. S. Slack, "Reactive oxygen species: stuck in the middle of neurodegeneration," Journal of Alzheimer's Disease, vol. 20, no. 2, pp. S357-S367, 2010.

[20] H. Kaneto, N. Katakami, M. Matsuhisa, and T.-A. Matsuoka, "Role of reactive oxygen species in the progression of type 2 diabetes and atherosclerosis," Mediators of Inflammation, vol. 2010, Article ID 453892, 11 pages, 2010.

[21] D. A. Patten, M. Germain, M. A. Kelly, and R. S. Slack, "Reactive oxygen species: stuck in the middle of neurodegeneration," Journal of Alzheimer's Disease, vol. 20, supplement 2, pp. S357S367, 2010.

[22] Z. Sroka and W. Cisowski, "Hydrogen peroxide scavenging, antioxidant and anti-radical activity of some phenolic acids," Food and Chemical Toxicology, vol. 41, no. 6, pp. 753-758, 2003.

[23] R. Masella, R. Varì, M. D’Archivio et al., "Extra virgin olive oil biophenols inhibit cell-mediated oxidation of LDL by increasing the mRNA transcription of glutathione-related enzymes," Journal of Nutrition, vol. 134, no. 4, pp. 785-791, 2004.

[24] R. Varì, M. D’Archivio, C. Filesi et al., "Protocatechuic acid induces antioxidant/detoxifying enzyme expression through JNK-mediated Nrf2 activation in murine macrophages," Journal of Nutritional Biochemistry, vol. 22, no. 5, pp. 409-417, 2011.

[25] A. Tarozzi, F. Morroni, S. Hrelia et al., "Neuroprotective effects of anthocyanins and their in vivo metabolites in SH-SY5Y cells," Neuroscience Letters, vol. 424, no. 1, pp. 36-40, 2007.

[26] G.-F. Shi, L.-J. An, B. Jiang, S. Guan, and Y.-M. Bao, "Alpinia protocatechuic acid protects against oxidative damage in vitro and reduces oxidative stress in vivo," Neuroscience Letters, vol. 403, no. 3, pp. 206-210, 2006.

[27] T.-H. Chou, H.-Y. Ding, R.-J. Lin, J.-Y. Liang, and C.-H. Liang, "Inhibition of melanogenesis and oxidation by protocatechuic acid from Origanum vulgare (Oregano)," Journal of Natural Products, vol. 73, no. 11, pp. 1767-1774, 2010.

[28] X. Zhang, G.-F. Shi, X.-Z. Liu, L.-J. An, and S. Guan, "Antiageing effects of protocatechuic acid from Alpinia on spleen and liver antioxidative system of senescent mice," Cell Biochemistry and Function, vol. 29, no. 4, pp. 342-347, 2011.

[29] S.-J. Tsai and M.-C. Yin, "Anti-glycative and anti-inflammatory effects of protocatechuic acid in brain of mice treated by dgalactose," Food and Chemical Toxicology, vol. 50, no. 9, pp. 3198-3205, 2012.

[30] Y. Semaming, S. Kumfu, P. Pannangpetch, S. C. Chattipakorn, and N. Chattipakorn, "Protocatechuic acid exerts a cardioprotective effect in type 1 diabetic rats," Journal of Endocrinology, vol. 223, no. 1, pp. 13-23, 2014.

[31] C. A. Feghali and T. M. Wright, "Cytokines in acute and chronic inflammation," Frontiers in Bioscience, vol. 2, pp. d12-d26, 1997.

[32] T. Lawrence and D. W. Gilroy, "Chronic inflammation: a failure of resolution?" International Journal of Experimental Pathology, vol. 88, no. 2, pp. 85-94, 2007.

[33] M. I. Fonseca, S.-H. Chu, A. M. Berci et al., "Contribution of complement activation pathways to neuropathology differs among mouse models of Alzheimer's disease," Journal of Neuroinflammation, vol. 8, no. 1, article 4, 2011. 
[34] R. Medzhitov, "Inflammation 2010: new adventures of an old flame," Cell, vol. 140, no. 6, pp. 771-776, 2010.

[35] A. M. Manicone and J. K. McGuire, "Matrix metalloproteinases as modulators of inflammation," Seminars in Cell and Developmental Biology, vol. 19, no. 1, pp. 34-41, 2008.

[36] T. Lawrence and C. Fong, "The resolution of inflammation: anti-inflammatory roles for NF- $\kappa \mathrm{B}$," The International Journal of Biochemistry \& Cell Biology, vol. 42, no. 4, pp. 519-523, 2010.

[37] S.-W. Min, S.-N. Ryu, and D.-H. Kim, "Anti-inflammatory effects of black rice, cyanidin-3-O- $\beta$-d-glycoside, and its metabolites, cyanidin and protocatechuic acid," International Immunopharmacology, vol. 10, no. 8, pp. 959-966, 2010.

[38] D. Wang, X. Wei, X. Yan, T. Jin, and W. Ling, "Protocatechuic acid, a metabolite of anthocyanins, inhibits monocyte adhesion and reduces atherosclerosis in apolipoprotein E-deficient mice," Journal of Agricultural and Food Chemistry, vol. 58, no. 24, pp. 12722-12728, 2010.

[39] D. Wang, T. Zou, Y. Yang, X. Yan, and W. Ling, "Cyanidin-3-O$\beta$-glucoside with the aid of its metabolite protocatechuic acid, reduces monocyte infiltration in apolipoprotein E-deficient mice," Biochemical Pharmacology, vol. 82, no. 7, pp. 713-719, 2011.

[40] J.-J. Yan, J.-S. Jung, Y.-J. Hong et al., "Protective effect of protocatechuic acid isopropyl ester against murine models of sepsis: inhibition of TNF-alpha and nitric oxide production and augmentation of IL-10," Biological and Pharmaceutical Bulletin, vol. 27, no. 12, pp. 2024-2027, 2004.

[41] E. D. Rosen and B. M. Spiegelman, "Adipocytes as regulators of energy balance and glucose homeostasis," Nature, vol. 444, no. 7121, pp. 847-853, 2006.

[42] E. Selvin, M. W. Steffes, H. Zhu et al., "Glycated hemoglobin, diabetes, and cardiovascular risk in nondiabetic adults," The New England Journal of Medicine, vol. 362, no. 9, pp. 800-811, 2010.

[43] D. M. Nathan, P. A. Cleary, J.-Y. C. Backlund et al., "Intensive diabetes treatment and cardiovascular disease in patients with type 1 diabetes," The New England Journal of Medicine, vol. 353, no. 25, pp. 2643-2653, 2005.

[44] J. R. Jones, C. Barrick, K.-A. Kim et al., "Deletion of PPAR $\gamma$ in adipose tissues of mice protects against high fat diet-induced obesity and insulin resistance," Proceedings of the National Academy of Sciences of the United States of America, vol. 102, no. 17, pp. 6207-6212, 2005.

[45] B. Scazzocchio, R. Varì, C. Filesi et al., "Cyanidin-3-O- $\beta$ glucoside and protocatechuic acid exert insulin-like effects by upregulating PPAR $\gamma$ activity in human omental adipocytes," Diabetes, vol. 60, no. 9, pp. 2234-2244, 2011.

[46] R. Harini and K. V. Pugalendi, "Antihyperglycemic effect of protocatechuic acid on streptozotocin-diabetic rats," Journal of Basic and Clinical Physiology and Pharmacology, vol. 21, no. 1, pp. 79-91, 2010.

[47] M. D’Archivio, C. Santangelo, B. Scazzocchio et al., "Modulatory effects of polyphenols on apoptosis induction: relevance for cancer prevention," International Journal of Molecular Sciences, vol. 9, no. 3, pp. 213-228, 2008.

[48] C. Giovannini, B. Scazzocchio, R. Varì, C. Santangelo, M. D’Archivio, and R. Masella, "Apoptosis in cancer and atherosclerosis: polyphenol activities," Annali dell'Istituto Superiore di Sanita, vol. 43, no. 4, pp. 406-416, 2007.

[49] J. Zhou-Stache, R. Buettner, G. Artmann, C. Mittermayer, and A. K. Bosserhoff, "Inhibition of TNF- $\alpha$ induced cell death in human umbilical vein endothelial cells and Jurkat cells by protocatechuic acid," Medical and Biological Engineering and Computing, vol. 40, no. 6, pp. 698-703, 2002.

[50] S. Guan, B. Jiang, Y. M. Bao, and L. J. An, "Protocatechuic acid suppresses $\mathrm{MPP}^{+}$-induced mitochondrial dysfunction and apoptotic cell death in PC12 cells," Food and Chemical Toxicology, vol. 44, no. 10, pp. 1659-1666, 2006.

[51] S. Guan, D. Ge, T.-Q. Liu, X.-H. Ma, and Z.-F. Cui, "Protocatechuic acid promotes cell proliferation and reduces basal apoptosis in cultured neural stem cells," Toxicology in Vitro, vol. 23, no. 2, pp. 201-208, 2009.

[52] S. Guan, Y.-M. Bao, B. Jiang, and L.-J. An, "Protective effect of protocatechuic acid from Alpinia oxyphylla on hydrogen peroxide-induced oxidative PC12 cell death," European Journal of Pharmacology, vol. 538, no. 1-3, pp. 73-79, 2006.

[53] H.-N. Zhang, C.-N. An, M. Xu, D.-A. Guo, M. Li, and X.-P. $\mathrm{Pu}$, "Protocatechuic acid inhibits rat pheochromocytoma cell damage induced by a dopaminergic neurotoxin," Biological and Pharmaceutical Bulletin, vol. 32, no. 11, pp. 1866-1869, 2009.

[54] T.-H. Tseng, C.-J. Wang, E.-S. Kao, and H.-Y. Chu, "Hibiscus protocatechuic acid protects against oxidative damage induced by tert-butylhydroperoxide in rat primary hepatocytes," Chemico-Biological Interactions, vol. 101, no. 2, pp. 137148, 1996.

[55] T.-H. Tseng, T.-W. Kao, C.-Y. Chu, F.-P. Chou, W.-L. Lin, and C.-J. Wang, "Induction of apoptosis by Hibiscus protocatechuic acid in human leukemia cells via reduction of retinoblastoma (RB) phosphorylation and Bcl-2 expression," Biochemical Pharmacology, vol. 60, no. 3, pp. 307-315, 2000.

[56] H.-H. Lin, J.-H. Chen, C.-C. Huang, and C.-J. Wang, "Apoptotic effect of 3,4-dihydroxybenzoic acid on human gastric carcinoma cells involving JNK/p38 MAPK signaling activation," International Journal of Cancer, vol. 120, no. 11, pp. 2306-2316, 2007.

[57] E. C. H. Yip, A. S. L. Chan, H. Pang, Y. K. Tam, and Y. $\mathrm{H}$. Wong, "Protocatechuic acid induces cell death in HepG2 hepatocellular carcinoma cells through a c-Jun N-terminal kinase-dependent mechanism," Cell Biology and Toxicology, vol. 22, no. 4, pp. 293-302, 2006.

[58] M.-C. Yin, C.-C. Lin, H.-C. Wu, S.-M. Tsao, and C.-K. Hsu, "Apoptotic effects of protocatechuic acid in human breast, lung, liver, cervix, and prostate cancer cells: potential mechanisms of action," Journal of Agricultural and Food Chemistry, vol. 57, no. 14, pp. 6468-6473, 2009.

[59] D. S. Peiffer, N. P. Zimmerman, L.-S. Wang et al., "Chemoprevention of esophageal cancer with black raspberries, their component anthocyanins, and a major anthocyanin metabolite, protocatechuic acid," Cancer Prevention Research, vol. 7, no. 6, pp. 574-584, 2014.

[60] V. Kuete, F. Nana, B. Ngameni, A. T. Mbaveng, F. Keumedjio, and B. T. Ngadjui, "Antimicrobial activity of the crude extract, fractions and compounds from stem bark of Ficus ovata (Moraceae)," Journal of Ethnopharmacology, vol. 124, no. 3, pp. 556-561, 2009.

[61] W. H. Liu, C. C. Hsu, and M. C. Yin, "In vitro anti-Helicobacter pylori activity of diallyl sulphides and protocatechuic acid," Phytotherapy Research, vol. 22, no. 1, pp. 53-57, 2008.

[62] M.-C. Yin and C.-Y. Chao, "Anti-Campylobacter, anti-aerobic, and anti-oxidative effects of roselle calyx extract and protocatechuic acid in ground beef," International Journal of Food Microbiology, vol. 127, no. 1-2, pp. 73-77, 2008. 
[63] P. Jayaraman, M. K. Sakharkar, C. S. Lim, T. H. Tang, and K. R. Sakharkar, "Activity and interactions of antibiotic and phytochemical combinations against pseudomonas aeruginosa in vitro," International Journal of Biological Sciences, vol. 6, no. 6, pp. 556-568, 2010.

[64] C.-Y. Chao and M.-C. Yin, "Antibacterial effects of roselle calyx extracts and protocatechuic acid in ground beef and apple juice," Foodborne Pathogens and Disease, vol. 6, no. 2, pp. 201-206, 2009. 


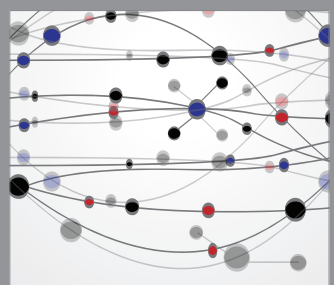

The Scientific World Journal
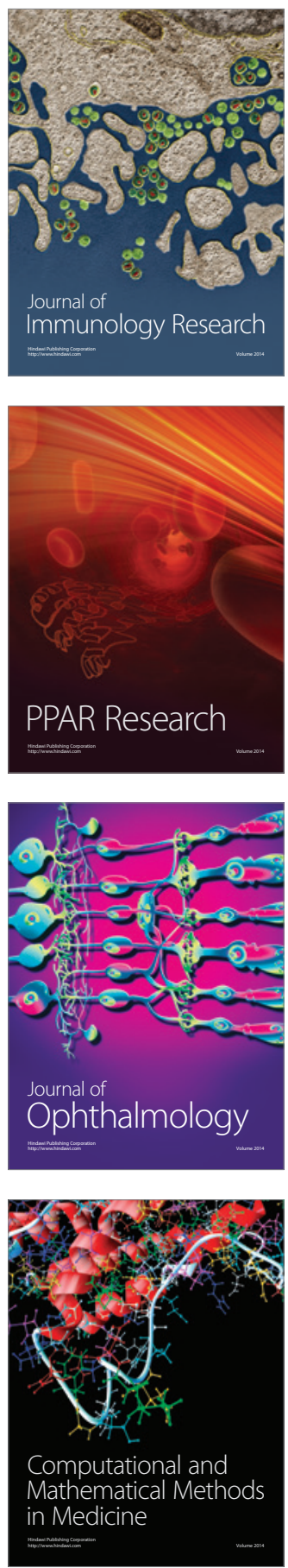

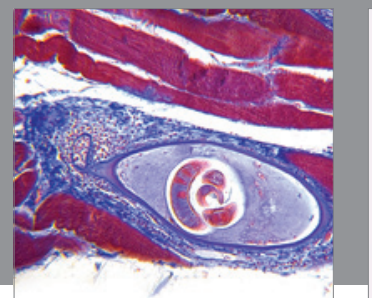

Gastroenterology

Research and Practice
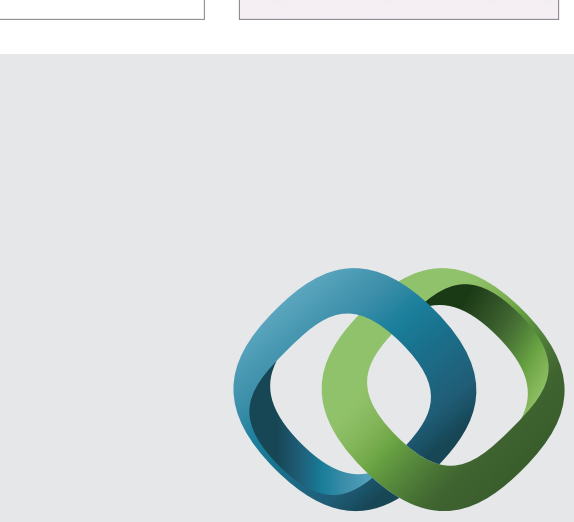

\section{Hindawi}

Submit your manuscripts at

http://www.hindawi.com
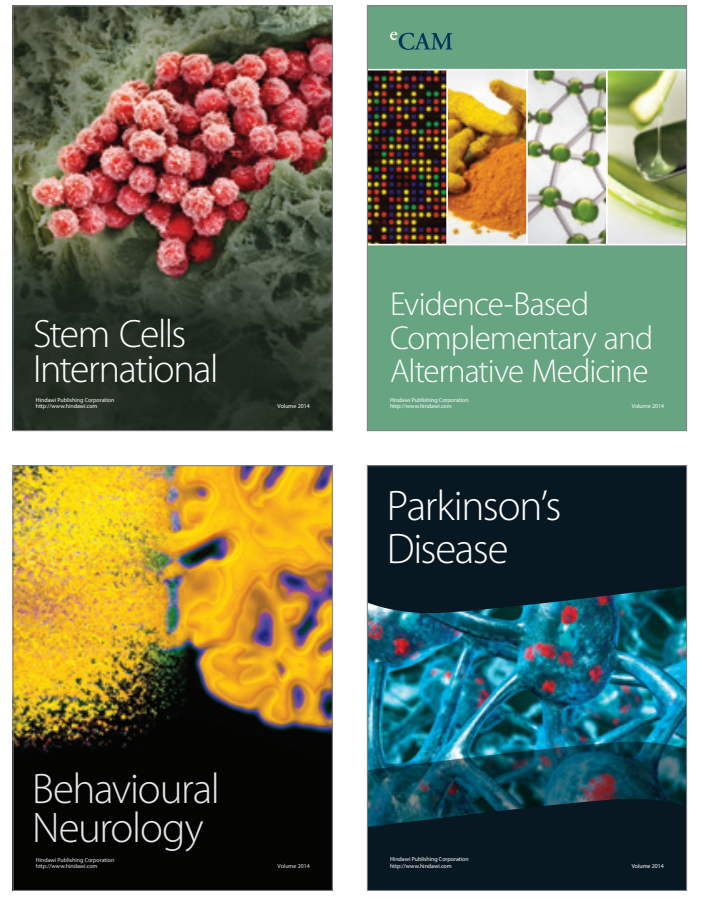
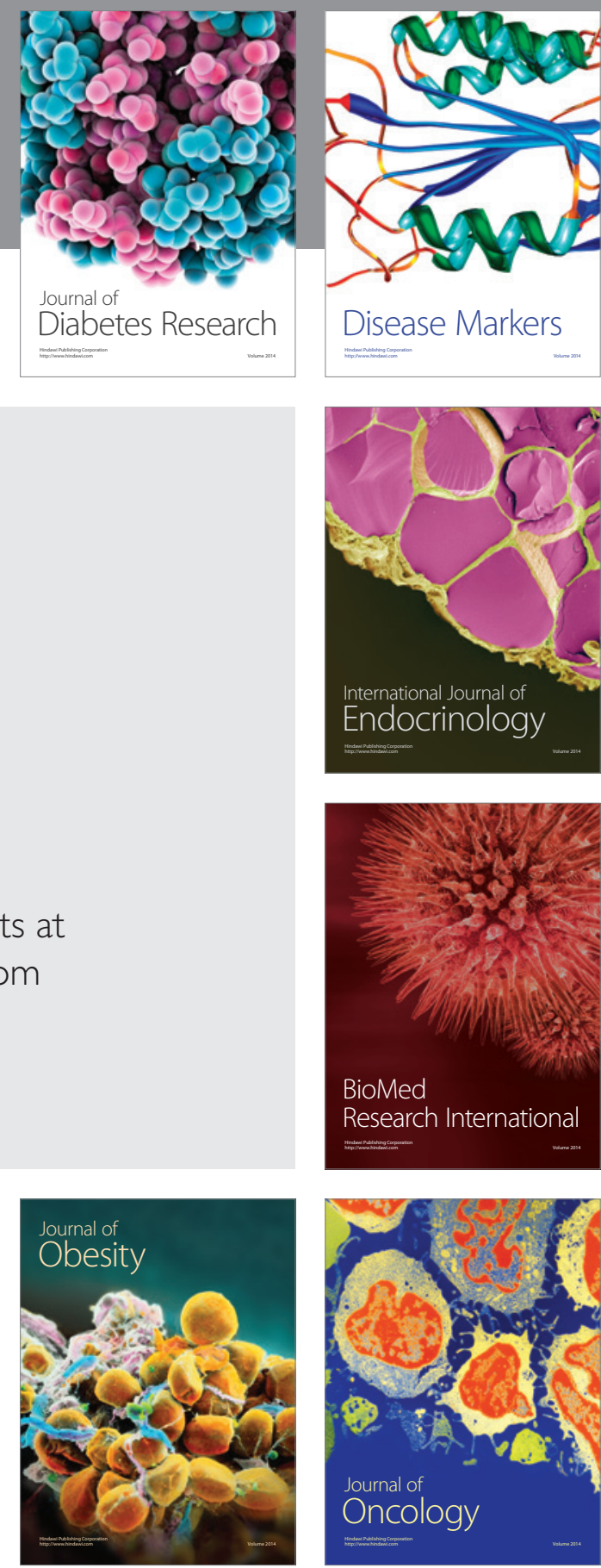

Disease Markers
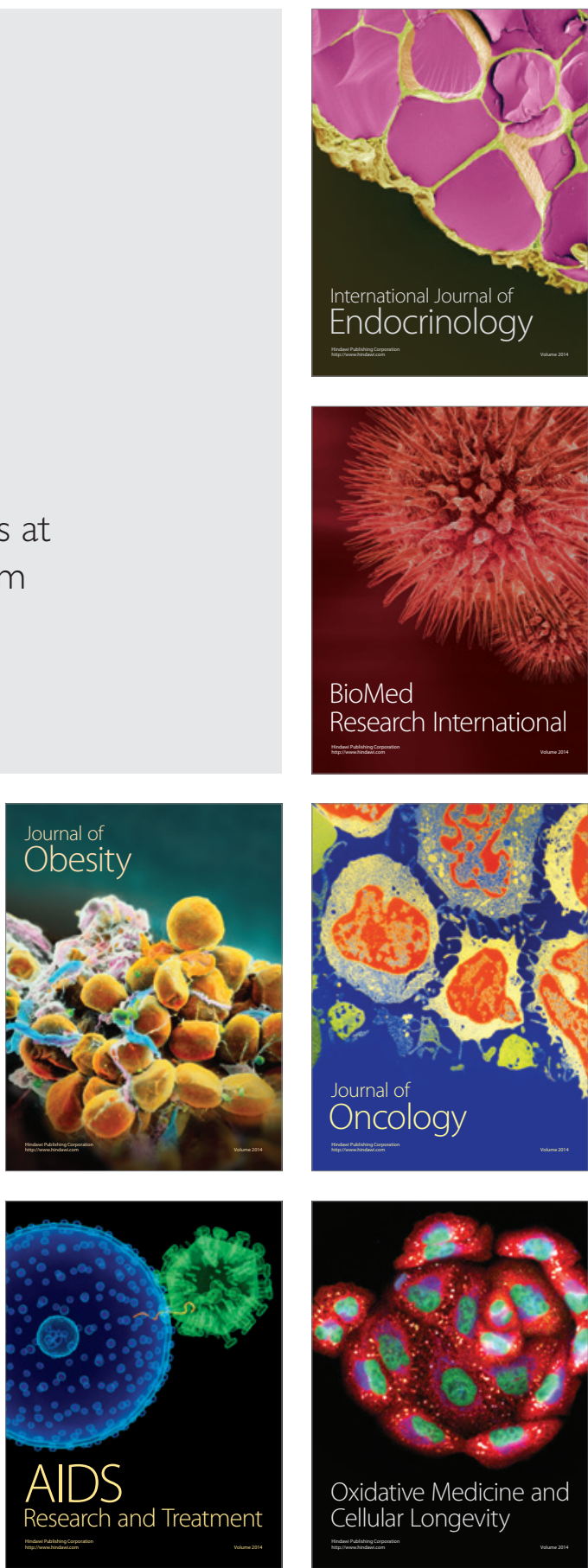